\title{
LA CODIFICACIÓN DEL DERECHO COMERCIAL CHILENO Y SUS EJES
}

\section{THE CODIFICATION OF CHILEAN COMMERCIAL LAW AND ITS AXIS}

\author{
Lorena Carvajal Arenas*
}

RESUMEN: Ante los factores que colocan en entredicho al Código de Comercio, como: la descodificación, la globalización y la naturaleza binaria del Derecho Comercial (el cual tiene raíces autoritarias y anárquicas), el artículo afirma la mantención de la forma código. El trabajo propone la revitalización del rol central del Código en el sistema jurídico, a través de la consagración de los ejes del Derecho Comercial moderno: los principios de la buena fe y de la autonomía de la voluntad, y la empresa.

Palabras clave: Código de Comercio, codificación, descodificación, principios, empresa

ABSTRACT: Before factors that undermine the Commercial Code, such as: laws going astray from the Code, globalization and the binary nature of Commercial Law (which has both "authoritarian and anarchical roots"), the paper argues the permanence of the Code. The study proposes the revival of the Code's central role in the legal system, throughout the enshrinement of the axis of modern Commercial Law: the principles of good faith and party autonomy, and the enterprise.

Key words: Commercial Code, codification, laws outside the Code, principles, enterprise

\section{INTRODUCCIÓN}

El proceso codificador y su producto, los códigos de Derecho privado de los siglos XVIII y XIX, cristalizaron los valores de la burguesía. Además, la codificación significó el encuadramiento del Derecho común conforme a la regulación de cada Estado nacional. De este modo, los códigos se tornaron imprescindibles para el funcionamiento de la sociedad de capitales.

En la actualidad, los códigos ya no operan como centro de la sociedad capitalista y tampoco simbolizan el zenit del nacionalismo jurídico. El fraccionamiento progresivo del sistema y la globalización del Derecho generan la necesidad de armonizar el Derecho Co-

* PhD, University of Portsmouth. Profesora de Derecho Comercial en la Pontificia Universidad Católica de Valparaíso. Dirección postal: Avenida Brasil 2950 Valparaíso. Correo electrónico: lorena.carvajal@pucv.cl Este trabajo forma parte de la investigación FONDECYT Nº 3140212

Las traducciones de fuentes legales, jurisprudenciales y doctrinales desde un idioma distinto al castellano han sido realizadas por la autora, a menos que se indique específicamente el origen de la traducción.

La autora agradece la lectura del borrador y los gentiles comentarios del profesor Pietro Masi y del Sr. Gonzalo Agliati. Un grato reconocimiento a los profesores del Departamento de Derecho Comercial de la Universidad de Chile: Sres. Octavio Bofill; Guillermo Caballero; Sebastián Obach; Álvaro Parra; y Arturo Prado, y al ayudante, Sr. Pablo Pavez, quienes comentaron acerca de las ideas fundamentales desarrolladas en este artículo, en el coloquio realizado el 7 de julio de 2016. Finalmente, un reconocimiento especial a la ayudante de Derecho Comercial de la Pontificia Universidad Católica de Valparaíso, Srta. Camila Quijano. 
mercial interno y también el Derecho de diversas jurisdicciones. Esto se produce especialmente en el ámbito comercial, donde la presión por la consistencia entre Derecho nacional y transnacional es una manifestación destacada de la influencia de la realidad en esta disciplina. Los elementos descritos, unidos a la importancia cada vez mayor del Derecho emanado de los propios operadores económicos, colocan en entredicho la "Forma código" en las jurisdicciones nacionales modernas. En Chile, la situación es aún más evidente debido a la obsolescencia de las instituciones reguladas en el Código de Comercio. Por lo tanto, se produce una tensión constante entre la praxis y la abstracción de las fórmulas codificadas ${ }^{2}$.

Este artículo analiza los argumentos que colocan en entredicho la forma código y sostiene que, a pesar de la expansión sin precedentes de la descodificación ${ }^{3}$ y de la globalización, la existencia del Código de Comercio en el sistema jurídico chileno es necesaria para mantener la coherencia del sistema. Además, este trabajo busca demostrar que la empresa ha llegado a ser una institución central del Derecho Comercial, al punto de obrar como matriz de los principios que estructuran dicho sistema: la buena fe y la autonomía de la voluntad. Por lo tanto, se concluye que, el reconocimiento de aquella institución permitiría ofrecer soluciones a una serie de aspectos relevantes del mercado actual.

La sección 1 contiene la discusión acerca de la permanencia o abolición de la forma código. La sección 2 se centra en el examen de la influencia de la empresa en el comercio moderno y en el desarrollo que, como consecuencia, han experimentado la autonomía de la voluntad y la buena fe. La sección 3, en virtud del examen de los efectos perniciosos que provoca la ausencia de una regulación general de la empresa en el Código, postula la necesidad de la incorporación del instituto en dicho cuerpo normativo. La sección final reagrupa las evidencias presentadas en las secciones precedentes para establecer las conclusiones generales.

\section{LA "FORMA" CÓDIGO}

El discurso de la codificación convoca y articula los grandes temas de la historia jurídica, porque cada código está esencialmente unido a la realidad jurídico-política de la sociedad en la cual se desarrolla. En esta línea, el autor Pio Caroni usa el viejo adagio " $u b i$ societas, ibi ius" en forma inversa, esto es, "ibi ius, ubi societas" para significar que el código deriva de una sociedad histórica ${ }^{4}$.

En el contexto liberal burgués en el cual surgen los códigos, el objetivo era hacer de estos cuerpos normativos el derecho privado aplicable en forma exclusiva para todo un pueblo de sujetos jurídicos formalmente iguales. El Derecho Comercial fue particularmente sensible a este ideal, pues no se limitó a los comerciantes, sino que se extendió a todo

\footnotetext{
1 Esta expresión es original de Rescigno (2004) p. 217.

Sobre el punto CoRradini (1982) p. 71.

3 El vocablo "descodificación" fue utilizado en el ámbito jurídico de manera original por Natalino Irti el año 1978. IRTi (1989).

4 Caroni (2012) p. XV.
} 
individuo que entrara en contacto con este Derecho5. Las codificaciones nacionales del siglo XVIII tenían pretensiones de totalidad o perfección en su regulación del caso genérico, aun a sabiendas de que lograr dicho fin es imposible. Esto se hizo porque las codificaciones debían servir derechos individuales, estándares de derechos humanos, proteger contra la interferencia gubernamental. En dicho contexto, los códigos contribuyeron a colocar la ley en un trono, porque ellos están estrechamente conectados con los ideales del positivismo y la "estatalización" del derecho. Con todo, en el ámbito comercial, las codificaciones que comenzaron a generarse a partir del s. XIX dejaron espacio al Derecho consuetudinario, porque la elaboración de normas privadas siempre ha jugado un rol significativo en la vida económica. Incluso hoy, a pesar de la gran cantidad de Derecho indisponible contenido en los códigos, muchas normas de naturaleza privada son fielmente observadas por los operadores comerciales.

Por lo tanto, el cuerpo de reglas relevante para el comercio está conformado por un mixto de normas originado en iniciativas públicas y privadas o a través de la cooperación de ambas. Esto se ha llamado "naturaleza binaria del Derecho Comercial"6, el cual tiene raíces autoritarias y anárquicas. La naturaleza binaria del Derecho Comercial puede apreciarse, entre otras manifestaciones, en el surgimiento, a partir de fines del siglo XX, de un número importante de compilaciones de Derecho Mercantil que contienen soft law, reflejo de la lex mercatoria internacional, como los Principios de UNIDROIT sobre Contratos Comerciales Internacionales ${ }^{7}$. El éxito de los Principios revela un compromiso tácito de los operadores de obedecer a la razón y a la justicia por la vía convencional, con el objeto de mantener una relación que puede generar rédito. Se unen la fuerza de la costumbre y la autonomía de la voluntad para el desarrollo de la cooperación entre los actores del comercio. En el Derecho uniforme comercial internacional la autonomía de la voluntad se ha ligado intrínsecamente con la libertad de comercio. Así ha sido consagrado en los referidos Principios en su artículo 1.1: "Las partes son libres para celebrar un contrato y para determinar

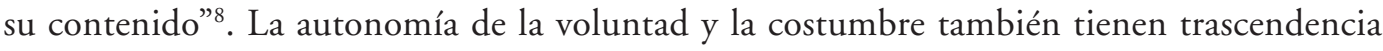
en el ámbito interno. Basedow indica que, "[l]a trasposición de la costumbre mercantil al Derecho estatal nunca ha sido absoluta o completa. De la misma forma, el Derecho Comercial nunca ha quedado encasillado en la ley nacional al mismo nivel del Derecho privado general"'.

El movimiento entre la autonomía privada y la regulación legal es constante en el Derecho Comercial. Hoy, lejos de los ideales de la sociedad burguesa que dio origen a los Códigos, los individuos reclaman por parte del Estado un tratamiento específico, privilegiado, lo cual genera cuerpos normativos ad hoc. Por otra parte, el propio Estado renuncia a su total imperium y se abre a la colaboración del ciudadano. Se trata de un Estado que para regular recurre al contrato y también a la sanción de un Derecho especial.

\footnotetext{
5 Es posible afirmar que el movimiento codificatorio concreta o complementa los ideales del movimiento constitucional que lo antecedió. En esta línea, Caroni (2011) p. 53.

6 BASEDOW (2008) p. 719.

7 LANDO (2003) pp. 123-133.

8 Illescas y Perales (2003) p. 37.

9 BASEDOW (2008) p. 706.
} 
La naturaleza binaria del Derecho Comercial, la tendencia hacia la armonización y unificación del Derecho Comercial nacional y transnacional, sumado a la descodificación -vale decir, la pluralidad de microsistemas, inspirado cada uno en sus propios principios y poseedor cada cual de su propia lógica ${ }^{10}$ - cuestionan el valor de la forma código en el contexto actual ${ }^{11}$.

Ante tal cuestionamiento, es posible consignar a favor del Código que, si este consagra los principios imperantes en el Derecho Comercial actual (tales como: predictibilidad; flexibilidad; autonomía de la voluntad y buena fe; un sistema eficaz de solución de controversias $^{12}$; mecanismos de acceso igualitario a los recursos financieros; transparencia e información; y eficacia de los mecanismos de tutela de los derechos), las leyes especiales podrían especificar aspectos singulares de dichos principios. Si la ley llamada "especial" debe delinear los conceptos basales para cada caso, deja de llamarse especial, pues, en realidad, es ajena al Código, porque regula instituciones de manera original y de forma integral. Si el Código se mantiene como el epicentro del ordenamiento jurídico privado, tiene lugar la relación entre Derecho general y Derecho especial, "el cual nace de la comparación de las dos normas jurídicas, las cuales tienen un elemento de hecho en común, en cuanto la norma más amplia comprende en su contenido el elemento de hecho de la menos amplia, y esta solamente le agrega un momento propio"13. En ese sentido, la referencia -formal y/o racional- permanente al código impide que la producción de reglas de derecho se disperse. Se acepta que, "[l]os códigos no garantizan la completa accesibilidad al derecho ni la certeza material de las decisiones jurídicas"14. A pesar de sus limitaciones, se estima que el código redunda en beneficio de "la estabilidad, continuidad y coherencia de los conceptos y de las estructuras jurídicas y, entonces, de la seguridad jurídica" ${ }^{15}$, porque, como fenómeno histórico, representa la congruencia entre la justicia material y los requerimientos éticos y socioeconómicos de la sociedad en la cual se inserta ${ }^{16}$. Si todo se deja a la ley especial, existe el riesgo que dichas leyes se transformen en legislación casuística o empírica, "al modo en que lo son las legislaciones arcaicas" ${ }^{17}$. Simplemente, se numeran elementos regulados por

\footnotetext{
10 GuZMán (1993) p. 43.

11 La utilidad de un Código para consagrar la materia comercial es un cuestionamiento radical. Una vez que se establece la importancia de la forma código en esta área, debería tener lugar la discusión relativa a la dicotomía civil y comercial del Derecho Privado. Bolaffio, Rocco y Vivante son partidarios de la unificación del derecho de las obligaciones civiles y mercantiles, aun cuando existe una diferencia entre la idea de Bolaffio y aquella de Rocco respecto a la relación de especialidad entre el Derecho Civil y el Derecho Comercial. Para el primero, ambas ramas son normas especiales en relación al Derecho Privado de las obligaciones. En cambio, para Rocco el Derecho Comercial, frente al Derecho Civil, es un derecho excepcional. Bolaffio (1947) pp. 10 y 11; RocCO (1931) pp. 58 ss.; ViVANTE (s.d.) p. 20. La diferencia de opiniones se reporta en Bolaffio (1947) p. 3.

12 BASKIND et al. (2013) pp. 4-7.

13 IRTI (1989) p. 25.

14 Accatino (2005) p. 195. En esta línea, Alejandro Guzmán reconoce que el "Derecho especial viene a ser casi un hecho consustancial a la existencia misma de los Códigos... La explicación de dicho fenómeno se encuentra en que los códigos intentan fijar el derecho, pero resultan impotentes para fijar el tráfico jurídico al que ese derecho se refiere". GuZmán (1977) p. 14. Alfange (1969) p. 65.

15 Oppetit (1991) p. 414.

16 GuZMÁN (1977) p. 12.

17 GuZMán (1993) p. 60.
} 
la ley, sin contar con construcciones dogmáticas que permitirían, en primer lugar, aprehender la ratio legis de la prescripción respectiva; y, en segundo lugar, determinar el criterio para reconducir los supuestos no regulados a un estatuto general superior ${ }^{18}$.

En este estado de la reflexión, favorable a la forma código, es necesario considerar la especificidad de la disciplina para determinar la procedencia -o improcedencia- de un Código de Comercio.

Para capturar la esencia de la comercialidad en la regulación del Código, este debe contener normas que permitan a los comerciantes certeza suficiente respecto al negocio actual y sus consecuencias y, al mismo tiempo, un nivel de flexibilidad que consienta a los operadores gestionar su negocio conforme a sus necesidades presentes y futuras. Se postula aquí que ambos objetivos pueden alcanzarse a través de un código de principios, de categorías generales y de instituciones cardinales (como la compraventa mercantil), los cuales configuran una estructura de Derecho común comercial ${ }^{19}$. Vivante consideraba que la labor del jurista es simplificar el derecho, componer un sistema lógico de principios y excepciones, que sea, al mismo tiempo, simple y capaz de resolver el mayor número posible de controversias $^{20}$. Un código que consagrara la autonomía de la voluntad y la buena fe como ejes permitiría acoger ese planteamiento. Respecto a la autonomía de la voluntad, es posible afirmar que, en los hechos, el contrato es el instrumento mediante el cual se realizan las innovaciones jurídicas en el comercio $^{21}$. Visionariamente, Mestre ponderaba en los años ochenta que el contrato ha llegado a ser un instrumento de colaboración entre las partes ${ }^{22}$. Es importante destacar que el contrato cumple ese rol a través de la consagración del principio de la buena fe, la cual ha sido entendida como cooperación de las partes en un contrato mercantil. La interpretación actual de la buena fe está estrechamente relacionada con la globalización del comercio en la segunda mitad del siglo XX y primeros años del siglo $\mathrm{XXI}^{23}$. En efecto, se ha observado que, con el objeto de asegurar oportunidades ventajosas y confiables (id est, con grados de certeza aceptables para decidir emprender el negocio),

18 Un buen ejemplo es la definición de empresa del art. $2^{\circ} \mathrm{N}^{\circ} 13$ de la LeY 20.720 de 2014, el cual, lejos de contener una fórmula dogmática abstracta acerca de la noción de empresa, se limita a ofrecer una numeración de fenómenos comprendidos bajo el término empresa para efectos de la legislación concursal.

19 La otra posibilidad es la codificación a droit constant, vale decir, la consolidación en un texto ordenado de la legislación vigente que se encuentra dispersa en numerosas fuentes legales y reglamentarias. Tal es la dirección del Código de Comercio Francés de 2001. Este Código es una compilación de estatutos sobre diversos temas, tales como: derecho societario; derecho de la insolvencia; títulos de crédito; prácticas comerciales; diversos contratos comerciales; etc. El Código también cuenta con normas generales sobre la organización del comercio, grupos de interés económico, ciertos tipos de ventas y cláusulas de exclusividad, entre otras normas. Ver. BorGHETTI (2013) pp. 181-201.

20 Vivante citado por Stella (2014) pp. 535 s.

21 Galgano (2005) pp. 8 y 93-114.

22 Mestre (1986) p. 101.

23 En el período previo, durante el siglo XIX, el individualismo contractual era la teoría en boga en el mundo civilizado. El movimiento que llevó los intereses del individuo al extremo fue reforzado por la tremenda influencia que el Darwinismo y el individualismo de Spencer ejercieron en esa época. Como es sabido, Darwin es el creador de la teoría de la evolución basada en el concepto de selección natural. Spencer se veía a sí mismo como un defensor de los principios liberales tradicionales contra el Estado, el cual, desde 1880 en adelante comenzó a asumir un rol fundamental. Ver TAYLOR (1996). 
el Derecho Comercial impone ciertas obligaciones de cooperación en la formación y ejecución de los contratos ${ }^{24}$. Respecto a este punto, Thomas Carbonneau observa que, "[l]os árbitros de la ICC consideran la obligación de buena fe como parte de los usos comerciales internacionales. La aplican como una cuestión de derecho. Esta idea de la buena fe como un elemento central de cohesión en la operatividad del comercio internacional está sustentada por la generalidad de laudos arbitrales internacionales y los comentarios académicos que los complementan"25.

En las legislaciones comparadas y en el Derecho internacional hay una serie de índices de cooperación contractual, también llamada "Justicia sustantiva en materia contractual”. En Derecho alemán, Cabrillac apunta que el éxito del Bürgerliches Gesetzbuch, $\mathrm{BGB}$, se debe a la consagración de cláusulas generales que corresponden en parte a principios, tales como la buena fe, lo cual facilitó su interpretación evolutiva por el juez ${ }^{26}$. La generalidad del $\$ 242$ BGB le ha permitido convertirse en una fuente de deberes, los cuales han llegado a ser independientes. Esto se ha denominado Ergänzungsfunktion. Las nuevas prescripciones del $\mathrm{BGB}$ que han integrado los desarrollos jurisprudenciales en torno al $\$ 242$ son: $\$ \$ 280$ (3); 282; y 241 (2) BGB, en virtud de las cuales el acreedor está autorizado no solo a obtener el cumplimiento, sino un cumplimiento cabal. Cada parte debe ser considerada en relación con los derechos e intereses de la otra. Esta perspectiva que incluye los deberes destinados a facilitar el cumplimiento de la otra parte, revela que existe una visión cooperativa de la relación contractual. Además, se ha dado importancia al cambio en las circunstancias que tenga tal entidad al punto de modificar los fundamentos del contrato. El cambio en las circunstancias (Störung der Geschaftsgrundlage) está consagrado en el $\$ 313$ BGB. También se contempla la posibilidad de terminar por una razón apremiante contratos de tracto sucesivo en el $\$ 314$ BGB. Otra institución es el Nachfrist, es decir, un período adicional para el cumplimiento. Esta institución -central en el nuevo Derecho de las obligaciones de Alemania, en materia de compraventa- es reconocible en cuerpos normativos de Derecho Comercial transnacional, tales como los Principios UNIDROIT sobre los Contratos Comerciales Internacionales (PICC, por sus siglas en inglés) art. 7.1.5; 27 $^{27}$ los Principios de Derecho Europeo de los Contratos (PECL, por sus siglas en inglés) arts. 9:301 (2) y 8:106 (3) ${ }^{28}$; y también en la Convención de Viena (CISG, conforme a su abreviación en inglés) art. 47.

\footnotetext{
24 Carvajal y Maniruzzaman (2012).

25 Carbonneau (1998) p. 17.

26 Cabrillac (2009) p. 304. Ante un cambio en las circunstancias, por ejemplo, es deseable la opción -consagrada en el Código- de reinterpretar y renegociar el contrato. En Derecho alemán, la buena fe mercantil ha permitido lograr un equilibrio entre la certeza del derecho y la flexibilidad que requiere la relación. Las partes de un contrato comercial de largo plazo pueden ser obligadas a renegociar si su relación sufre un deterioro. Al respecto, KÖNDGEN y Borges (2005) p. 130.

27 En este artículo se trabaja con la versión oficial en español del 2010:

http://www.unidroit.org/spanish/principles/contracts/principles2010/blackletter2010-spanish.pdf. Fecha de consulta: 10 de julio de 2016

${ }_{28}$ La versión en español se encuentra en el siguiente enlace: http://campus.usal.es/ -derinfo/Material/LegOblContr/PECL\%20I+II.pdf. Fecha de consulta: 10 de julio de 2016.
} 
Asimismo, la Ordenanza N²016-131 de 10 de febrero de 2016 sobre la Reforma del Derecho de los Contratos y el Esquema General de Prueba de las Obligaciones de Francia contempla instituciones que revelan la tendencia en el sentido de la justicia contractual $^{29}$. Entre otras, el art. 1169 introduce al Code Civil la sanción de las cláusulas abusivas; también se introduce expresamente en el art. 1195 la teoría de la imprevisión. De esta forma, en caso de un cambio de circunstancias imprevisible al tiempo de la celebración del contrato que hace la ejecución excesivamente onerosa para una parte que no había aceptado asumir tal riesgo, surge la obligación de renegociación del contrato. Se establece, además, una limitada facultad al juez para revisar el acuerdo. Una reciente, mas constante, jurisprudencia de la Cour de Cassation consagra esta solución ${ }^{30}$.

Por lo tanto, se considera que la noción de buena fe-cooperación -la única que se adecua a la experiencia del comercio actual- debería ser incorporada como principio rector del Código de Comercio moderno y obrar como fulcro de sus instituciones ${ }^{31}$.

Queda aún pendiente determinar qué criterio debería delimitar las materias sujetas al Código. Tradicionalmente, el sistema comercial codificado chileno se considera objetivo, es decir, basado en la ejecución de determinados actos calificados como "actos de comercio" numerados en el art. $3^{\circ}$ del Código del ramo ${ }^{32}$. En la misma línea, Rocco, a pesar de que reconoce a la industria comercial y fabril como la matriz del comercio, ensalza la universalización del Derecho Comercial a través de la consagración del acto de comercio en el Código italiano de 1882: "tanto se ha extendido hoy el campo de aplicación del Derecho mercantil, que no solo la industria comercial, sino también la industrial fabril está sujeta en una buena parte al Derecho mercantil, y esta expansión continuada del ámbito del Derecho mercantil es actualmente tal, que hay una multitud de actividades pertinentes a otras ramas de la producción, que no son actos de producción económica, y, sin embargo, caen bajo los preceptos del Derecho comercial" ${ }^{33}$. Puga, conocedor de las dificultades que provoca la numeración del artículo $3^{\circ}$ del Código de Comercio en Chile (principalmente, porque no permite incluir nuevos actos), postula una interpretación alternativa a la teoría tradicional. Él considera que, "[l]a mercantilidad se refiere a las actividades económico privadas que reseña el artículo $3^{\circ}$ y los actos y contratos que los profesionales de dichas actividades celebran para el ejercicio de las mismas son mercantiles por accesión a dicha actividad" ${ }^{34}$. Si se sigue lógica del autor italiano y la interpretación un poco más avanzada del autor nacional, la idea que a continuación se desarrollará en este artículo, vale decir, la consagración de la empresa como eje del Código, podría significar un retroceso, pues implicaría la consagra-

\footnotetext{
29 La Ordenanza se encuentra disponible en: https://www.legifrance.gouv.fr/eli/ordonnance/2016/2/10/JUSC1522466R/jo/texte Fecha de consulta: 4 de octubre de 2016

30 Momberg (2015) p. 135.

31 Carvajal (2014) pp. 659-684. "El deber de buena fe y actuación leal (fair dealing) cumple su función esencial a través de la protección de las expectativas legítimas que las partes no han reducido a un lenguaje contractual expreso". VAn Alstine (1998) p. 1228.

32 La crítica a la teoría objetiva puede consultarse en: CARVAjAl (2015) pp. 3-24.

33 Rocco (1931) p. 5. Sobre la consagración del acto de comercio en el Código de 1882: Rocco (1931) p. 48. Sobre la amplitud del ámbito comercial, Rocco (1931) p. 49.

34 Puga (2013) p. 112
} 
ción de un Derecho profesional. Precisamente, los párrafos siguientes pretenden demostrar que, debido al rol central de la empresa en el comercio moderno, el Código debe consagrarla como su eje para regular adecuadamente el mercado. En este punto, es importante adelantar que el concepto de empresa se ha ampliado notablemente para comprender a la empresa de servicios (se incluye la actividad profesional o artística organizada), a la producción y comercialización de intangibles (productos financieros, por ejemplo), e, incluso, a la producción e intermediación de bienes y servicios sin fines de lucro, o sea, a unidades económicas donde el lucro se vierte en la propia organización -para el desarrollo de su giro-, o en el territorio en el cual ejecuta sus operaciones. La noción de empresa comprendería también a las unidades económicas que exceden la clasificación estricta "con o sin fin de lucro", como en las cooperativas, donde los excedentes se reparten de manera equitativa entre los socios, sin atender al aporte de capital ${ }^{35}$.

Como se adelantó, en las siguientes secciones se desvela el rol de la empresa en el comercio moderno y la importancia de su incorporación en el código ${ }^{36}$.

\section{LA EMPRESA}

\subsection{LA INFLUENCIA DE LA EMPRESA EN EL COMERCIO}

Thorstein Veblen, un clásico de la literatura económica y de la sociología moderna y, al mismo tiempo, un crítico del capitalismo, reconoce en su obra "Teoría de la Empresa de Negocios" de 1904 que, "[e]n mayor grado que en cualquiera de las otras etapas culturales conocidas, el mundo cristiano deriva su naturaleza de su organización económica... El sistema industrial es la estructura material de la civilización moderna y la empresa de negocios es la fuerza directiva que lo anima" ${ }^{37}$.

El concepto actual de empresa es fruto de una transición desde una empresa de negocios (siglo XIX) hacia una empresa industrial (siglo XX). Hoy, ambas encierran aquello que se entiende como empresa. La figura del empresario y, por consiguiente, de la empresa que desarrolla su actividad en virtud de un contrato comenzó a desaparecer a medida que el proceso de industrialización devino más importante y el capital relevante pasó de ser aquel comercial a aquel industrial. El empresario pasó de ser un especulador a un productor de

35 El propio legislador alemán reconoció esta evolución de la empresa -y, por consiguiente, la necesidad de aplicación del Derecho especial a un universo mayor- en la reforma del derecho comercial alemán de 1998 (Handelsrechtsreformgesetz 1998) extendió la definición de comerciante, de modo que hoy incluye a todas las empresas. Excepcionalmente, no incluye la agricultura $\$ 3$ (I) HGB y los pequeños negocios. Con todo, cualquier persona que se desenvuelva en el mundo de los negocios -incluso agricultores y pequeños empresariostiene la opción de ser un comerciante a través del registro de su negocio en el Registro de Comercio Handelsregister $\$ \$ 2,3 \mathrm{HGB}$. Profesionales permanecen fuera de la regulación comercial. Si estas personas optan por desarrollar su actividad profesional bajo la forma de una sociedad, típicamente de responsabilidad limitada, entonces se les considera como comerciantes. Sobre la reforma al Derecho alemán puede consultarse, KöNDGEN y Borges (2005) p. 122.

36 Caballero considera que la concepción profesional del Derecho Comercial ha sido incorporada al ordenamiento jurídico chileno a través de la ampliación de la mercantilidad "por razón de la forma" en las estructuras de organización de la empresa, tales como la sociedad anónima, la empresa individual de responsabilidad limitada y la sociedad por acciones. Ver. Caballero (2013) pp. 447-457.

37 Veblen (2009) p. 3. 
riqueza, quien en la actualidad produce directamente para el mercado. En un estadio posterior, el empresario comenzó a especular sobre los valores derivados de los productos o commodities $^{38}$.

La evolución de la empresa, hasta convertirse en el motor del sistema económico moderno, ha dado lugar al proceso de comercialización del Derecho privado ${ }^{39}$. Este fenómeno se ha producido gradualmente como consecuencia de la primacía de la riqueza dinámica (capital y actividad especulativa organizados a través de la empresa) por sobre la riqueza estática (propiedad de la tierra y hereditaria), y progresiva disolución de la sociedad patriarcal ${ }^{40}$. La experiencia jurídica de los últimos dos siglos registra el surgimiento de un conjunto de relaciones e institutos que se caracteriza por tener su centro en el rol y en la función económico-jurídica de la empresa comercial ${ }^{41}$. Consecuentemente, algunos sistemas jurídicos, como el Código Civil italiano de 1942 y el Código Civil brasileño de 2002, han optado por establecer a la empresa como centro de la regulación comercial contenida en los respectivos códigos civiles unificados ${ }^{42}$.

Por una parte, el concepto de empresario se introdujo en el sistema del Derecho privado de Italia por el Código Civil de 1942 en el art. 2082. Dicho concepto sustituyó a aquel del comerciante, en razón del "Método de la economía", pues se deseaba que las formas jurídicas fueran correspondientes a la realidad económica. Se consideraba que la empresa tenía un rol fundamental en el comercio como sostén del proceso económico. Por lo tanto, la institución devino central en el Código. Como, a su vez, la figura clave de dicha realidad es el empresario, el sistema legal debía fundarse en dicho concepto ${ }^{43}$. Antes, en Latinoamérica, Siburu -con una visión muy adelantada para su tiempo- trató de localizar el significado de la empresa en la economía política y, de esa forma, consideraba que los factores de la producción eran: naturaleza; capital y trabajo, los cuales organizados u "obrando en concierto" formaban el concepto de empresa. El autor atribuía relevancia al pensamiento director que lleva a cabo el empresario, quien toma de su cuenta el riesgo de la actividad, condición inseparable de toda empresa ${ }^{44}$. Volviendo a Italia, cuando se comenzó a hablar del "Derecho empresario" o "Derecho de la empresa" en los años '50s y, especialmente, cuando se produjo el auge en los años '70s, se pensaba en la cogestión, la cual implica que empresario y trabajadores administran conjuntamente una empresa. El Derecho empresario comprendía, por tanto, al Derecho Laboral de la empresa ${ }^{45}$. En esa línea, como el Derecho Comercial consagrado en el Código Civil italiano de 1942 surgió en el contexto

\footnotetext{
38 Larry Neal sitúa el inicio del capitalismo financiero en una etapa anterior al surgimiento del propio capitalismo industrial. Para él, la historia del capitalismo financiero comienza con la "revolución del precio" ("price revolution") del s. XVI en Europa, la cual podría ser calificada como la "Primera revolución financiera". NEAL (1990) p. 3.

39 Carvajal (2006) p. 42.

40 Kozolchyк (1979) pp. 3-47.

41 Galgano (2013) p. 2.

42 Cerami y Petrucci (2004) pp. 10-11.

43 Galgano (2013) p. 4.

44 Siburu (1923) p. $108 \mathrm{~N}^{\circ} 300$.

45 Schmidt (1997) pp. 10-11.
} 
del corporativismo, donde la cogestión es clave, se incluyó al Derecho Laboral en el Libro Quinto Título II llamado "Del lavoro nell'impresa”, el cual contiene normas generales sobre actividades profesionales ${ }^{46}$. El Codice Civile comprende al empresario entre los trabajadores no subordinados que desarrollan actividad económica. El empresario es un trabajador que se incluye en una categoría específica, debido al riesgo técnico y económico que implica y su importancia para el desarrollo de la economía. En todo caso, la opción del legislador fue resaltar al empresario antes que a la empresa ${ }^{47}$. El legislador italiano sabía que, "las disposiciones deberían tener como foco la actividad desarrollada en el tiempo y dispuesta para la creación de riquezas, razón por la cual debería ser ejercida de forma continuada, por lo tanto, profesionalmente" 48 .

Por otra parte, el Libro II del Código Civil brasileño se titula: "Do Direito de empresa". El art. 966 establece: "[s]e considera empresario a quien ejerce profesionalmente actividad económica organizada para la producción o circulación de bienes o de servicios”. Dicha actividad es desarrollada por la empresa ${ }^{49}$. Sobre la evolución desde el antiguo Derecho de los comerciantes hacia el Derecho Comercial como Derecho de la empresa, Bulgarelli se pronuncia: "Como la empresa pasó a dominar la economía moderna, tenía, fatalmente, que encontrar, más tarde o más temprano, un lugar en el Derecho. Aun cuando se había entrometido, prácticamente, en todos los ramos del Derecho, el lugar central, que le es propio, está en el Derecho Comercial" 50 .

Allende la relevancia económica, desde el punto de vista jurídico, la empresa es una institución generadora de normas comerciales. Esta función se cumple a través de la creación de contratos atípicos, fundamentalmente transnacionales. La autonomía de la voluntad ha adquirido tal relevancia que, como indica Galgano, si un tiempo los contratos servían para hacer circular cosas; hoy sirven también para hacerlas, para crear productos financieros ${ }^{51}$. Desde mediados del siglo XX, el desenvolvimiento de las actividades de cada empresa se liga en forma exponencial a su colaboración con otras ${ }^{52}$. En consecuencia, se ha producido una variación del foco desde la consideración del acto o contrato específico hacia la relación contractual entre las partes ${ }^{53}$. El nuevo enfoque en la relación, más que

\footnotetext{
46 Sobre el ordenamiento corporativo fascista -el cual se enfrentó al corporativismo católico- en Italia, DE NAPOLI (1976) pp. 325-336. Sobre el corporativismo católico. Correa (2008) pp. 467-481.

47 "El Código Civil italiano de 1942 superó la tradicional contraposición entre industria y comercio, por una parte, y agricultura y artesanía, por otro... se delineó una noción general y unitaria de empresario" CAMPOBASSO (2014) p. 11

48 SZTAjn (2004) p. 60.

"El Codice italiano funda en la empresa la comercialidad, se concibe un Derecho de la nueva economía sobre una base objetiva, con la empresa al centro del sistema” RondinOnE (2003) p. 107. Este autor concibe el establecimiento de la empresa como base de un sistema objetivo, porque la subjetividad en dicho contexto hubiera significado establecer como centro a las corporaciones.

49 SZTAjN (2004) pp. $86 \mathrm{~s}$

50 Bulgarelli (1984) p. 14.

51 Galgano (2005) pp. 18, 20 y 94; Marchese (2010).

52 Forgioni (2010) pp. 175 ss.

53 "[l] as relaciones de largo tiempo y las redes contractuales están siendo usadas de manera creciente en economías desarrolladas y en vías de desarrollo" Gómez (2011) pp. 21, 30, 25.
} 
en el acto específico, y la consecuente necesidad de flexibilidad de las normas que rigen el contrato, ha generado una revalorización del aspecto consuetudinario del Derecho Comercial $^{54}$. En razón de la economía de la transacción, la regulación por la voluntad de las partes de todos los detalles no es viable. Por lo tanto, renace la fuerza de la costumbre mercantil para llenar los vacíos regulatorios y permitir el ajuste del contrato conforme a la evolución de la relación ${ }^{55}$. Un agente propulsor de este nuevo contexto regulatorio es la empresa. La dinámica de los cambios acelerados y profundos que se produjeron como consecuencia de la intensificación del comercio (facilitada por el desarrollo de la tecnología y la facilidad de desplazamiento de personas y mercaderías) determinó que el Derecho nacional y las necesidades económicas se distanciaran. Por lo tanto, los operadores del mercado comenzaron a regularse ellos mismos a través de contratos estándar y a través de las regulaciones de las asociaciones de comerciantes. Las primeras áreas de la actividad comercial que comenzaron a desarrollar sistemáticamente sus propias reglas contractuales fueron las industrias del transporte y de seguros. Röder llama a este fenómeno "[l]a colonización del derecho contractual por los hombres de negocios y por las compañías"56. Dado que las empresas concentran cada vez más mayor poder económico, han masificado las técnicas de contratación creadas o adaptadas a sus necesidades por ellas mismas ${ }^{57}$. Como resultado, las empresas han llevado a cabo la armonización del Derecho Privado a través de un ordenamiento legal distinto a aquel nacional y a aquel transnacional emanado de los Estados ${ }^{58}$. Esta es la llamada "Lex mercatoria moderna"

El curso seguido por este ordenamiento de los operadores y empresas es muy interesante, pues ha sido posteriormente "codificado" a través de guías-legislativas o principios que se ofrecen a los gobiernos para asistirlos en la elaboración de políticas y legislación comercial nacional, como por ejemplo: la Guía Legislativa UNCITRAL sobre Derecho de la Insolvencia (2004); la Guía de UNIDROIT sobre Franquiciado Principal (Master Franchise Agreement 1998/2007); los Principios sobre Gobiernos Corporativos de la OECD (2004); y la Guía Legislativa de la CNUDMI sobre las Operaciones Garantizadas (2007). De esta forma, el Derecho emanado de las empresas retroalimenta el Derecho transnacional, el cual -a su vez- influencia de manera determinante la legislación interna.

54 Carvajal y Manurizzaman (2012).

55 Rescigno advierte el peligro de una regulación entregada a la costumbre: "El peligro, como demuestra la lex mercatoria, es que la falta de invasión del derecho estatal se traduzca en definitiva en el derecho del más fuerte, el derecho de las clases hegemónicas que también por esta vía logren tener el monopolio de la producción jurídica y una incidencia decisiva sobre la vida de los hombres.” ResCigno (2004) p 219.

56 RÖDER (2006) para. 7.

57 EtcheVerry (2004) pp. 133-178, específicamente, p. 168.

58 Vogenauer hace notar que las convenciones son notoriamente inflexibles porque su revisión necesita otra ronda de negociaciones y ratificaciones. Su capacidad para enmiendas subsecuentes que permitan adaptarlas al ambiente rápidamente cambiante de comercio internacional es, por tanto, extremadamente limitado. VoGENAUER (2015) p. 4.

59 Las siguientes obras claves: BERGER (2010); y CARBOnNEAU (1998). 
La centralidad de la empresa ${ }^{60}$ y el cambio que esta ha producido en el modo de regular la actividad económica indican que dicha institución debería ser definida y ser regulada sistemáticamente en el Código de Comercio. Esta hipótesis se revisa en el siguiente apartado y en la sección 3.

\subsection{El CONCEPTO DE EMPRESA EN EL DERECHO COMERCIAL}

Tradicionalmente, el Derecho ha reconocido el fenómeno económico de la empresa, a fin de atribuirle consecuencias jurídicas. En contra de esta visión tradicional, Eric Orts sostiene la prevalencia del sistema jurídico, por sobre la economía, para describir y entender el fenómeno de la empresa ${ }^{61}$. La utilización de la palabra "fenómeno" no es aleatoria, pues el autor sostiene que, a pesar de que las empresas comerciales deben cumplir con los requisitos legales, ellas también se crean y diseñan a ellas mismas y, luego, hacen un requerimiento para tener un derecho de existencia independiente y para tener reconocimiento legal. Orts -quien, como se ha dicho, postula la importancia de considerar la naturaleza legal de la empresa como una "ficción" pero aun social y legalmente una institución y una persona jurídica "real" - sostiene que quienes defienden las teorías de la empresa llamadas "contractualistas"62, o sea, aquellas que ven a la empresa como un nexo de una miríada de contratos (de compraventa, de servicios, de trabajo, de suministro, etc.) no logran reconocer que las instituciones o grupos también existen (como una categoría ontológica) de manera autónoma respecto de los miembros individuales que la componen ${ }^{63}$.

Esta posición, innovadora desde el punto de vista de su construcción metodológica, ha sido recogida, en los hechos, por el Código de Comercio chileno, el cual reconoce a la empresa subyacente a la tipología societaria -e incluso más allá de los sujetos que la componen-. Así lo demuestra el reconocimiento de las 'sociedades de hecho' ${ }^{\prime 4}$. La justificación de las sociedades de hecho reside en el acuerdo de los asociados, alcanzado de forma tal que estos razonablemente reputan que existe una sociedad, y, por lo tanto, desarrollan la actividad empresarial bajo esa vestidura. Esta visión da relevancia a la "realidad de la empresa"65. Asimismo, un pronunciamiento de la Corte Suprema utiliza la expresión "proyecto empresarial" para referirse a la situación a la base de una sociedad de hecho ${ }^{66}$.

\footnotetext{
60 Para ponderar el impacto de las operaciones de empresas multinacionales (EMN), se considere el caso de los Estados Unidos y Japón, donde la inversión extranjera directa global y la producción internacional de dichas empresas han crecido más rápido que el PIB o el comercio internacional. UNCTAD World Investment Report (2015) p. 74. Disponible en: http://unctad.org/en/PublicationsLibrary/wir2015_en.pdf. Fecha de consulta: 13 de julio de 2016.

${ }^{61}$ ORTS (2013). Las teorías económicas de la empresa se refieren a todas las unidades productivas, sin importar cómo se organizan. Las teorías legales de la empresa, en cambio, tienden a centrarse en la sociedad. BRATTON (1989) pp. 1471-1527.

62 Estas teorías son conocidas como "Contractarian theories". Millon (1993) pp. 1373-1393.

63 OrTs (2013) capítulo 1 y p. 64. En contra, en los hechos, Raúl Etcheverry, quien opina que la empresa no es una categoría jurídica. Su concepto global solo sería posible desde el punto de vista económico y sociológico. Esta teoría es calificada como "atomista", porque cada elemento de la empresa está regido por la ley que le corresponde’. ETCHEVERRY (2004) p. 151.

64 Torres (1998) pp. 193-198.

65 Arts. 356, 357 inc. $2^{\circ}$, 358 y 359 del Código de Comercio.

${ }_{66}$ MARTÍNEZ CON SANTORO (2003). Los considerandos 8 y 10 son pertinentes en la presente discusión.
} 
A pesar del reconocimiento intrínseco de la realidad empresarial, que aquí se propone, el concepto de empresa presente en el Código chileno y, en general, en los códigos del siglo XIX, refleja un estado de la economía en el cual no era la industria sino el comercio el motor del desarrollo económico. La empresa manufacturera era regulada junto a aquella de comisión y de transporte, porque en todas estas figuras el empresario trabajaba en virtud de una orden o encargo. El concepto de empresa reflejaba una concepción mercantil que no comprendía la actividad industrial. Era una categoría jurídica de intercambio, la cual indicaba una actividad de intermediación o de especulación relativa al trabajo, en cuanto el empresario desarrollaba su actividad interponiéndose entre quien solicita determinados servicios y la fuerza de trabajo necesaria para producirlos. El empresario ganaba la diferencia entre ambos. Como es sabido, el proceso de industrialización de la economía determinó un cambio de paradigma, acorde con el dato real relativo a la forma de organizar el comercio, el cual significó incorporar en el concepto de empresa a la producción directa para el mercado. Ese dato - la concepción moderna de la empresa- no está recogido en el Código de Comercio chileno. En consecuencia, el Código no considera el impacto que tal institución ejerce en el Derecho Comercial.

Hoy la empresa es una noción referida a la actividad económica organizada de producción y circulación de bienes y servicios para el mercado, ejercida profesionalmente. Además, se considera que la empresa es una unidad de producción e intercambio cuya eficiencia y contribución al bien común es deseable ${ }^{67}$. Lorenzo Mossa, precursor en Italia de la noción que postula que el Derecho Comercial ha sido dictado esencialmente para los comerciantes y, por lo tanto, para las empresas ${ }^{68}$, argumentaba su posición sobre la idea que la empresa cumple su función siempre al servicio de la comunidad: "Como en el Derecho Civil, la organización jurídica está dirigida a satisfacer exigencias de la vida del hombre y de la familia, así en el Derecho Comercial el ordenamiento jurídico está dirigido en primer lugar a satisfacer las exigencias de la vida de las empresas. Si el fin supremo de nuestro Derecho Comercial es la organización jurídica del comercio, es cierto que esta se identifica principalmente con la organización jurídica de la empresa. La empresa es considerada como una persona económica, que se proyecta en el campo jurídico por su actividad y sus exigencias, unida fuertemente con las exigencias de la comunidad"69.

Por lo tanto, si bien, en principio, el Derecho Comercial dirigía sus normas a la empresa capitalista ${ }^{70}$, hoy, en cambio, el Derecho Comercial ha experimentado una reorientación, porque regula también a las empresas cuyo fin no es el lucro de manera exclusiva o principal. Galgano indica que "El Código Civil ha adoptado una noción unitaria de empresa; y esta noción unitaria de empresa, comprensiva tanto de la empresa privada como de la empresa pública, constituye la confirmación ulterior de la irrelevancia, para el Derecho vigente, del antiguo requisito del fin de lucro, no siendo posible de otra forma explicar cómo y porque -en el sistema legal- se incluye entre los empresarios a los agentes públicos que

\footnotetext{
67 Este elemento no es original de esta época, solo ha retomado vigor últimamente. El corporativismo del siglo XX consideraba de manera esencial los fines sociales de la empresa, aunque, en los hechos, esta finalidad se pervirtió a causa de los sistemas políticos que lo adoptaron. De NAPOLI (1976).

68 Casi contemporáneamente, WiELAND exponía el derecho subjetivo alemán, recurriendo constantemente al sistema subjetivo francés e italiano, ordenándolo unitariamente según el concepto de empresa. EsPINA (2006) p. 15 nota 9.

69 Mossa (1926) pp. 245-246.

70 SCHMidT (1997) p. 12.
} 
tienen por objeto una actividad comercial organizada, eso si bien, por regla general, tales entes no se proponen, con sus actividades, finalidades especulativas, sino múltiples finalidades de interés social"71. A propósito, Pietro Masi resalta en su trabajo "Empresa multinacional" que la opción de llamarla "empresa" puede ser objeto de observaciones críticas por la potencialidad del término de comprender organismos que en los diversos ordenamientos no reciben necesariamente una calificación empresarial, por ejemplo, por la ausencia de un fin de lucro ${ }^{72}$. En esta línea, la amplitud del concepto de empresa permite incluir a las cooperativas $^{73}$ y a las empresas sociales ${ }^{74}$.

Por otra parte, no es posible ignorar la evolución de las técnicas de ejercicio de algunas profesiones liberales, la cual denota su "comercialización", en el sentido que es posible comprenderlas dentro de la actividad de empresa para efectos de determinar la disciplina aplicable, siempre que se trate de una actividad tendente a la producción o intercambio de bienes o servicios, desarrollada en forma organizada y profesional ${ }^{75}$. Estas condiciones son requeridas por el Codice Civile italiano para considerar como tales a las profesiones intelectuales y artísticas, conforme a lo que señala el art. 2238 inc. $1^{\circ}$. Este punto ha asumido ribetes interesantes en Brasil, donde las actividades intelectuales y profesiones liberales no se comprenden como actividad de empresa en el art. 966 del Código Civil de 2002, pero sí han quedado comprendidas por el Proyecto de Código de Comercio para la nación brasile$\tilde{\text { na }}{ }^{76}$.

En síntesis, una noción actual de empresa debería comprender a la actividad organizada de producción y circulación de bienes y servicios para el mercado, la cual puede estar estimulada por objetivos que exceden el lucro de sus agentes. Como tal, la empresa moderna persigue, entre otros objetivos, la materialización del bien común y la defensa del valor de la reciprocidad en la conducta económica ${ }^{77}$. Esta noción puede aplicarse a la actividad de artistas e intelectuales, en la medida que se trate de operaciones organizadas y habituales.

Las posibilidades de materializar los aspectos favorables que la empresa produciría si se regula en el Código de Comercio se responden en la siguiente sección.

\footnotetext{
71 Galgano (2013) p. 11.

72 MASi (2002) pp. 508-525.

73 El art. $1^{\circ}$ del DFL N ${ }^{\circ} 5$ de 2003 contiene una definición de cooperativa para el ordenamiento chileno. Con todo, el art. $1^{\circ}$ de la Ley 27/1999, de Cooperativas de España enfatiza el rol social de este tipo de empresas.

74 VÁsquez y Juppet (2014). El sitio de la división de asociatividad y economía social del Ministerio de Economía es: http://economiasocial.economia.cl/

75 Por profesionalidad se entiende habitualidad. Galgano (2013) p. 9.

76 A favor de la inclusión de las profesiones liberales como actividades empresariales, SERRA (2004) p. 86: "La disciplina de la empresa no excluye la disciplina de las profesiones intelectuales, sino que concurre con ella, de modo que la calificación de empresario resulta compatible -en el plano de la disciplina aplicable- con aquella de quien ejerce una profesión intelectual". En los hechos, en contra de este autor y, explícitamente, en contra de la dirección asumida por el Proyecto de Código de Comercio: Valladāo y França (2013) pp. 32-37.

77 Zamagni (2013) pp. 286 ss.
} 


\section{IMPORTANCIA DE LA REGULACIÓN DE LA EMPRESA EN EL CÓDIGO}

Es posible constatar que la ausencia de una regulación fundamental de la empresa mercantil en el ordenamiento jurídico chileno incide negativamente en una serie de aspectos que se detallarán a continuación.

En primer lugar, dicha situación ha generado que las llamadas "leyes especiales" definan en cada caso qué se entenderá por empresa ${ }^{78}$. El problema es que, en vez de tratarse de especificaciones del fenómeno que, en general, el Derecho chileno califica como empresa, cada rama o subrama del Derecho ofrece una regulación completa del fenómeno empresarial. Por lo tanto, es imposible señalar en términos generales qué fenómenos deben sujetarse a un tipo de normas que, en su conjunto, constituyen el estatuto de la actividad productiva identificable como empresa y, en consecuencia, los supuestos no regulados no pueden ser reconducidos a un estatuto general superior ${ }^{79}$.

En segundo lugar, la falta de regulación de la empresa en la legislación comercial se revela como un problema cuando es necesario determinar responsabilidades de carácter civil, penal o administrativo de la matriz por actividades de la sociedad controlada en el caso de los grupos empresariales. Como no hay una concepción de la empresa comercial, se atiende a las estructuras societarias que constituyen el grupo. Excepcionalmente, se ha atribuido la responsabilidad a los controlantes de la empresa que el grupo de sociedades conforma. En el caso de Catrilef Hernández, Salomón y otros con Pesca Cisne S.A. la Corte de Apelaciones de Punta Arenas indicó que, la actuación "se imputará directamente a los socios o a los controlantes que hicieron posible (la violación de la ley, del orden público o de la buena fe), quienes responderán solidaria e ilimitadamente por los perjuicios causados" (paréntesis agregado $)^{80}$.

Jesús María Silva Sánchez, a propósito de la dictación en España, el 2010, de una Ley sobre responsabilidad penal de la persona jurídica ${ }^{81}$, "alude a la existencia de dos nociones de base: la de la responsabilidad de la persona jurídica y la de la responsabilidad penal de la empresa. Según la primera no deberían ser hechas responsables sociedades matrices por hechos cometidos en las filiales; ni tampoco deberían ser hechas responsables las sociedades sucesoras por hechos cometidos por las sucedidas. En cambio, la idea de responsabilidad penal "de la empresa" permitiría salvar estas fronteras a partir de la idea de empresa como unidad económica (el grupo es una unidad económica) que se prolonga en el tiempo más allá de la duración de una determinada forma jurídica (en la sucesión de empresas, tras una disolución de personas jurídicas). La responsabilidad de la persona jurídica debe repu-

\footnotetext{
78 Por ejemplo, la Ley No 20.720 de 2014 en el art. $2^{\circ}$ N $^{\circ} 13$ indica, a través de la definición de empresa, que los procedimientos concursales para las empresas deudoras están dirigidos a personas jurídicas (con y sin fines de lucro) y a personas naturales contribuyentes de primera categoría o del número 2) del artículo 42 del decreto LEY No 824, del Ministerio de Hacienda, de 1974, que aprueba la ley sobre impuesto a la renta.

79 Cetra (2014) \$1 n. 9.

80 Catrilef Hernández, Salomón y otros con Pesca Cisne S.A. (2008). Este caso fue citado recientemente en Sociedad inmobilliaria E INVERsiones RamaQ LtDa. con GonZalo Santolaya IngENieros consultores S.A. (2015). UGARTE (2012) p. 706.

81 En Chile la responsabilidad penal de la persona jurídica fue acometida por la Ley Nº 20.393 de 2009.
} 
tarse responsabilidad individual. La responsabilidad de la empresa debe reputarse responsabilidad colectiva en sentido estricto" 82 .

En tercer lugar, además de los supuestos de responsabilidad del grupo, pueden presentarse situaciones que caben dentro de la legalidad, pero que conducen a resultados inaceptables. Por ejemplo, podría presentarse la paradoja que la matriz pueda exigir derechos en el procedimiento concursal de la controlada, en circunstancias que las directrices de la primera han determinado la insolvencia de la segunda ${ }^{83}$. Esto acarrea una serie de consecuencias desde diversos puntos de vista, entre otros, en el ámbito del gobierno corporativo, pues, a través del nombramiento de los directores, la matriz tiene un control real en las operaciones y decisiones de la filial. Por lo tanto, las sociedades que forman parte del grupo empresarial actúan en la vida económica y jurídica tomando ventaja de la personalidad jurídica que les aporta la sociedad ${ }^{84}$.

En Chile, de manera excepcional, algunos fallos han dado solución a estos casos por medio de la aplicación de la doctrina del levantamiento del velo ${ }^{85}$ : "Salvo determinadas excepciones jurisprudenciales, la tendencia mayoritaria en la práctica jurídica nacional ha sido intentar otras alternativas que ofrece el Derecho, como la acción pauliana, la acción ordinaria de responsabilidad extracontractual o la acción de inoponibilidad, para lograr el pago frente a deudores relacionados, por ejemplo, con grupos empresariales" ${ }^{\prime 6}$.

También algunos tribunales norteamericanos han hecho caso omiso de las personalidades jurídicas de cada sociedad y han atribuido la responsabilidad en el patrimonio de la matriz, generalmente a través de la doctrina del levantamiento del velo societario, cuando en los hechos las sociedades han actuado como un todo indivisible, es decir, como una empresa única ${ }^{87}$. Los patrones comúnmente utilizados por los tribunales norteamericanos

82 Silva (2013) p. 244. El profesor Jesús Ma. Silva a propósito de este tema cita a: Von Frier (2009) pp. 98116.

83 Esta posibilidad es planteada por Jequier (2015) p. 200. El art. 63 de la LeY $\mathrm{N}^{\circ} 20.720$ sanciona la intervención de partes relacionadas (art. $2^{\circ} \mathrm{N}^{\circ} 26$ letra b) en el procedimiento de reorganización con la posposición o subordinación legal de créditos indocumentados 90 días antes de la apertura del procedimiento concursal. Una norma similar se encuentra en el art. 241 inc. fine de la LEY No 20.720 para el caso de la liquidación. La ratio legis en estos casos es evitar "el riesgo de la alteración del pasivo mediante la creación de créditos relacionados no justificados”. Goldenberg (2015) p. 102. Dichas normas no niegan la intervención de la matriz en el procedimiento concursal de la controlada; solamente subordinan la recuperación o pago del crédito en los casos señalados (créditos no documentados).

84 La situación es diferente en el Derecho del Trabajo. La LEY No 20.760 de 2014 abordó la práctica empresarial de crear múltiples sociedades, no obstante, se tratase de una única empresa, a través de la modificación del art. $3^{\circ}$ del Código del Trabajo. El texto actual de dicho artículo indica en lo pertinente: "Dos o más empresas serán consideradas como un solo empleador para efectos laborales y previsionales, cuando tengan una dirección laboral común, y concurran a su respecto condiciones tales como la similitud o necesaria complementariedad de los productos o servicios que elaboren o presten, o la existencia entre ellas de un controlador común”. Ver la opinión emitida durante la tramitación del Proyecto popularmente conocido como "Ley del Multirut" en UGARTE (2013) p. 185-213.

85 JeQUiER (2014) pp. 147 y 138.

86 Urbina (2011) p. 164.

${ }^{87}$ Aun cuando la doctrina del levantamiento del velo fue elaborada, originalmente, para proteger a los accionistas individuales de su responsabilidad por los negocios de la sociedad, las ideas que cada sociedad tiene su propia existencia jurídica y que los accionistas tienen responsabilidad limitada se extendieron a las matrices- 
para aplicar esta teoría incluyen evadir obligaciones o deberes preexistentes, así como la extracción o mezcla de patrimonios. En todo caso, los estándares utilizados son muy diversos. Strasser analiza varios de estos parámetros para concluir que la visión del "Derecho de la Empresa" -o sea, el análisis si formalmente partes separadas llevan a cabo colectivamente una empresa única integrada bajo el control de la matriz o si actúan como entes separadosdebe servir para determinar la aplicación o no del levantamiento del velo societario ${ }^{88}$.

Adolf Berle, quien, en los años treinta, postulaba que la sociedad (corporate entity) obtiene su ser a partir de la realidad de la empresa subyacente -formada o en formaciónilustra con un caso real la ventaja que reporta el reconocimiento de la empresa ${ }^{89}$. En el caso Cintas v. American Car and Foundry Co. ${ }^{90}$ el demandante pretendía obtener el pago de dividendos privilegiados de manera prioritaria a los dividendos ordinarios. Conforme a la legislación de New Jersey, si el dividendo se había producido efectivamente, el demandante estaba revestido de dicha prioridad para obtenerlo. El punto central era, por lo tanto, determinar si el dividendo se había generado. La principal defensa era que, mientras la sociedad en la cual el demandante tenía acciones preferentes mostraba ganancias en sus estados financieros, estas estaban más que equiparadas por las pérdidas sufridas por las filiales de la sociedad. Si se consideraba los estados financieros consolidados de todas las sociedades que formaban el holding, las ganancias, que estaban a la base de la reclamación del demandante, desaparecían. Con todo, el tribunal se aferró a la tipología societaria. Por lo tanto, el demandante obtuvo en el juicio, a pesar de que la empresa como un todo consolidado demostraba no haber obtenido los dividendos en cuestión. La doctrina de la empresa habría conducido a un resultado más sano, porque, realísticamente, si se considera el hecho económico, el demandante no estaba autorizado a recibir dividendos y, probablemente, se habría considerado ilegal la actuación de la sociedad que los hubiera pagado ${ }^{91}$.

Este ejemplo sugiere para el caso chileno que el reconocimiento de la empresa permitiría que, cuando la sociedad fuera cuestionada, los tribunales tuvieran a la empresa debidamente regulada para dirigir su acción -o intervención- y no tendrían recurrir a ficciones jurídicas o creaciones ad hoc.

accionistas de sociedades controladas, precisamente cuando se abrió esta posibilidad de tenencia accionaria alrededor de los inicios del siglo XX. BlumberG (2005) pp. 605-618.

88 "Los méritos doctrinales de la "empresa de negocios única" son interesantes... Sin embargo, no existe un movimiento general que consagre esta visión más allá de su adopción en Texas y Luisiana y con limitada aplicación en algunos otros pocos Estados, hasta ahora". STRASSER (2005) p. 647.

89 Berle (1947) pp. 354 s. En contra, en los hechos, Di SABATo (2004) p. 2493, quien postula la posibilidad de una sociedad sin empresa.

90 Cintas v. AmERICAN CAR AND Foundry Co., 131 N.J.Eq. 419 (1942).

91 La práctica del cash pooling o financiamiento intragrupo a través de la gestión centralizada de tesorería no considera los documentos que indican la existencia de una o más personas jurídicas dentro de la empresa, sino que considera a la empresa como un todo para lograr objetivos contables. El cash pooling atiende a la realidad empresarial. Ver CARVAJAL (2007). En el ámbito del financiamiento intragrupo centralizado se encuentra también el cash management, esto es, la planificación y gestión centralizada de la liquidez del todo el grupo, a través de la constitución de una cuenta corriente intragrupo gestionada por la matriz o una de las sociedades del grupo. Ver Schneider (1985) pp. 995-1039. 
Adicionalmente, se describe a continuación un instituto que ilustra cómo la empresa, regulada de manera general en el Código, permite la evolución del Derecho en contextos distintos del comercial. Se trata del "pacto de familia" introducido en el Codice Civile italiano por la Ley No 55 de $2006^{92}$.

El art. 768 bis del Codice Civile califica el pacto de familia como el contrato por medio del cual "el empresario transfiere, en todo o en parte, la azienda, y el titular de participaciones en una sociedad transfiere, en todo o en parte, las propias cuotas, a uno o más descendientes". Este pacto significa una derogación parcial de la prohibición de celebrar pactos sucesorios, según el art. 458 del mismo Código. Por una parte, se encuentran los "bienes de empresa" (el establecimiento de comercio y las cuotas sociales), cuya transferencia se permite a título de liberalidad a los descendientes del empresario -de modo de evitar reclamaciones posteriores de los legitimarios-. Por otra parte, se encuentran los restantes bienes, respecto de los cuales continúan operando las disposiciones vigentes en línea con la tradición romanística, entre otros, la señalada prohibición de pactos sucesorios ${ }^{93}$. A través de la aplicación del pacto de familia se logra un efecto de estabilidad en la continuación de la empresa. Al mismo tiempo, es posible el "paso generacional" de la pequeña y mediana empresa $^{94}$, evita la fragmentación del control y, en definitiva, se proyecta en la eficiencia de la gestión empresarial. Como es esperable, estos elementos favorecen la competitividad del mercado ${ }^{95}$.

En Chile, el art. 2103 del Código Civil, aplicable a las sociedades colectivas comerciales por expresa disposición del art. 407 del Código de Comercio, permite la persistencia de la sociedad con los herederos del difunto, siempre que el contrato de sociedad colectiva prevea la cláusula de sucesión, es decir, una cláusula que ordena o autoriza la continuidad de la sociedad con la sucesión del socio fallecido. Por lo tanto, la continuidad de la empresa en el ordenamiento jurídico nacional, al menos en este caso, aún está ligada a la forma societaria $^{96}$.

\section{CONCLUSIÓN}

El Código de Comercio de 1865 ha dejado de ser el centro de la experiencia jurídica contemporánea. La pérdida de influencia deriva no solo de la multiplicidad de leyes especiales reguladoras de situaciones del comercio moderno, sino que, además, de una serie de factores, tales como: leyes ajenas al Código (descodificación); la globalización y la sempiterna importancia de las regulaciones emanadas de las partes y de la costumbre mercantil.

\footnotetext{
92 Las normas del Codice que se refieren a este tema son: arts. 458, 768 bis y ss.

93 Petrelli (2006) pp. 401-447.

94 Tal como lo sugería la Recomendación de la Comisión de la CEE de 7 de diciembre de 1994 que contenía una invitación a promover la continuidad y la transferencia generacional de la empresa. Ver Gallo (1998).

95 MASI (2010) pp. 1031-1041.

96 Nótese que todos los herederos ocupan la posición del socio-causante (art. 2201 inc. $2^{\circ}$ del Código Civil). "De allí, entonces, que la cláusula de sucesión no constituye un pacto de sucesión futura, pues no dispone sobre bienes hereditarios" Caballero (2015) p. 255.
} 
Se considera beneficioso que el Código de Comercio recobre su posición como piedra angular del sistema jurídico chileno. Eso ocurrirá si está conformado por principios del Derecho Comercial. En esa línea, se desarrolló la tesis del reconocimiento de la autonomía de la voluntad y de la buena fe como principios rectores de las instituciones del Código.

Se establece, igualmente, la necesidad de reconocer a la empresa en el Código de Comercio, pues la naturaleza particular de esta institución ha aportado características decisivas, de forma y fondo, para la conformación del Derecho Comercial nacional e internacional $^{97}$. La empresa ha llegado a ser el organismo económico que concentra los medios y los sujetos que ejercen la actividad mercantil. Esta crea, además, gran cantidad de las reglas a las cuales se sujetan los negocios. La consagración de la empresa en el Código permitiría fijar reglas generales sobre una serie de aspectos trascendentes para mercado actual, tales como la responsabilidad de la matriz por actos que afectan a una filial o a todo el grupo económico. Así, las leyes especiales y los operadores jurídicos (estos últimos a través del ejercicio de la autonomía privada y de incorporación de la buena fe) podrían establecer efectos jurídicos ulteriores respecto de aquello regulado con carácter general en el Código. Esto conformaría un verdadero sistema de Derecho Comercial.

\section{BIBLIOGRAFÍA CITADA}

Accatino, Daniela (2005): "Métodos de codificación y racionalización del Derecho", De la codificación a la descodificación. Code Civil (1804-2004) Código de Bello (1855-2005) (Santiago, Ediciones Universidad Diego Portales) pp. 191-200.

Alfange, Dean Jr. (1969): "Jeremy Bentham and the Codification of Law", Cornell Law Review, vol. LV, No 1: pp. 58-77.

Barros, Enrique (2004): "Sentidos y métodos de la codificación en el Derecho", De la codificación a la descodificación. Code Civil (1804-2004) Código de Bello (1855-2005) (Santiago, Ediciones Universidad Diego Portales) pp. 151-161.

BASEDOW, Jürgen (2008): "The State's private law and the economy: commercial law as an amalgam of public and private rule-making", The American Journal of Comparative Law, vol. LVI, No 3: pp. 703-721.

Baskind, Eric; Osborne, Greg y Roach, Lee (2013): Commercial Law (Oxford, Oxford University Press).

Berger, Klaus Peter (2010): The creeping codification of the Lex Mercatoria (Alphen aan den Rijn, Kluwer Law International, segunda edición).

Berle, Adolf (1947): "The theory of enterprise entity", Columbia Law Review, vol. XLVII, No 3: pp. 343-358.

Blumberg, Phillip (2005): "The transformation of modern corporation law: the law of corporate groups," Connecticut Law Review, vol. XXXVII: pp. 605-618.

Bolaffio, Leone (1947): Derecho Comercial. Parte General, Volumen I (trad. Delia Viterbo y Santiago Sentis, Buenos Aires, Ediar Editores).

97 SAndoval (2009) pp. 31 y s. 
Borghetti; Jean-Sébastien (2013): "French Law", en Rivera, Julio César (edit.), The scope and structure of civil codes (Dordrecht, Springer) pp. 181-201.

Bratton, William (1989): "The new economic theory of the firm: critical perspectives from history", Stanford Law Review, vol. LXI, No 6: pp. 1471-1527.

Bulgarelli, Waldírio (1984): A teoría jurídica da empresa. Tese de concurso para o provimento de cargo de professor titular de Direito Comercial da Universidade de São Paulo (São Paulo) Editorial USP.

Caballero, Guillermo (2015): "Comentario de jurisprudencia. Sociedad colectiva comercial. Pacto de continuación forzosa de la sociedad. Solidaridad. Sentencia de la Corte Suprema de 6 de enero de 2015, rol 9976-2014", Revista Chilena de Derecho Privado, No 24: pp. 251-258.

Caballero, Guillermo (2013): "Comentario de jurisprudencia. Declaración de quiebra de un deudor calificado. Carácter siempre mercantil se una sociedad anónima. Sentencia de la Corte Suprema, 29 de agosto de 2013, rol 33092013”, Revista Chilena de Derecho Privado, No 21: pp. 447-457.

Cabrillac, Rémy (2009): Las codificaciones (trad. Paulina Pulido Velasco y Claudia Bulnes Olivares, Santiago, Flandes Indiano).

Campobasso, Gianfranco (2014): Manuale di Diritto Commerciale (Turín, UTET).

Carbonneau, Thomas (1998): "A definition of and perspective upon the lex mercatoria debate", en Carbonneau, Thomas (edit), Lex Mercatoria and Arbitration. A Discussion of the New Law Merchant (Londres, Kluwer Law International).

Caroni, Pio (2012): Escritos sobre la codificación (Madrid, Editorial Dykinson).

Carvajal, Lorena (2006): "La unificación del Derecho de las obligaciones civiles y comerciales", Revista de Derecho, vol. XXVII: pp. 37-53.

Carvajal, Lorena (2007): Il finanziamiento intragruppo. Tesi del Master in Diritto Commerciale Internazionale (di Roma Università La Sapienza).

Carvajal, Lorena y Maniruzzaman, Munir (2012): "Cooperation as philosophical foundation of good faith in international business-contracting. A view through the prism of transnational law". Disponible en: http://ouclf.iuscomp.org/articles/carjaval_maniruzzaman.shtml Fecha de consulta: 2 de mayo de 2016.

Carvajal, Lorena (2014): "La buena fe en Derecho continental y en Derecho anglosajón", en Jequier, Eduardo (edit.) Estudios de Derecho Comercial IV (Santiago, Thomson Reuters) pp. 659-684.

Carvajal, Lorena (2015): "De los actos de comercio a la teoría de la empresa: sus posibilidades en la codificación chilena', en CABALLERo, Guillermo y LAGOS, Osvaldo (edits.), Estudios de Derecho Comercial V (Santiago, Thomson Reuters) pp. 3-24

Cerami, Pietro y Petrucci, Aldo (2004): Diritto commerciale romano: profilo storico (Turín, Giappichelli, segunda edición).

Cetra, Antonio (2014): Diritto Commerciale (Turín, Giappichelli).

Corradini, Domenico (1982): Historicismo y politicidad del derecho (Madrid, Revista de Derecho Privado).

Correa, Sofía (2008): "El corporativismo como expresión política del socialcristianismo", Teología y Vida, vol. XLIX: pp. 467-481. 
De Napoli, Domenico (1976): "El corporativismo en Italia. Aspectos históricos y doctrina”, Revista de Estudios Politicos, N²06-207: pp. 325-336.

Di Sabato, Franco (2004): "La nozione di impresa nell'ambito delle organizzazioni non profit" en Studi in onore di Piero Schlesinger (Milano, Giuffrè) pp. 2491-2500.

Espina, Daniel (2006): La empresa en el Derecho Mercantil (Barcelona, Atelier).

Etcheverry, Raúl (2004): "La empresa en el Código de Comercio y en el Derecho Venezolano", en Morles, Alfredo y de Valera, Irene (edits.), Centenario del Código de Comercio Venezolano (Caracas, Academia de Ciencias Políticas y Sociales).

Forgioni, Paula (2010): Teoria geral dos contratos empresariais (São Paulo, Editora Revista dos Tribunais, segunda edición).

Galgano, Franceso (2005): La globalizzazione nello specchio del diritto (Bologna, Il Mulino).

Galgano, Franceso (2013): Diritto Commerciale. L'Imprenditore - Le società (Bologna, Zanichelli, octava edición).

Gallo, Miguel Ángel (1998): “La sucesión en la empresa familiar”. Disponible en:

http://www.fundacionregional.com.ar/download/Gallo_sucesion_01.pdf

Fecha de consulta: 5 de julio de 2016.

GoldenberG, Juan Luis (2015): "Los créditos legalmente pospuestos en la Ley 20.720", Revista de Derecho, vol. XXVIII, N²: pp. 91-116.

Gómez, Fernando (2011): "Cooperation, long-term relationships and open-endedness in contractual networks", en CAFAGGI, Fabrizio, Contractual networks, inter-firm cooperation and economic growth (Cheltenham, Edward Elgar) pp. 21-38.

GUZMÁn, Alejandro (1977): La fijación del derecho (Valparaíso, Ediciones Universitarias).

GuZMÁn, Alejandro (1993): "Codificación, descodificación y recodificación del derecho civil chileno”, Revista de Derecho y Jurisprudencia, vol. XC, No 2: pp. 39-62.

Illescas, Rafael, Perales, Pilar (2003): Derecho Mercantil Internacional. El Derecho Uniforme (Madrid, Editorial Centro de Estudios Ramón Areces).

IRTI, Natalino (1989): L'età della decodificazione (Milano, Giuffrè, tercera edición).

Jequier, Eduardo (2015): "Grupos empresariales e insolvencia. Aproximación al estatuto de responsabilidad del administrador de hecho en la Ley $\mathrm{N}^{\circ} 20.720$ ", en Caballero, Guillermo y Lagos, Osvaldo (edits.), Estudios de Derecho Comercial V (Santiago, Thomson Reuters) pp.187-245.

Jequier, Eduardo (2014): "Premisas para el tratamiento de los grupos empresariales y administradores del hecho en el Derecho chileno", Revista Chilena de Derecho, vol. XLI, No 1: pp. 121-152.

Köndgen, Johannes y Borges, Georg (2005): “Commercial Law”, en Reimann, Mathias y ZeKOlL, Joachim (edits.), Introduction to German Law (Alphen aan den Rijn, Kluwer Law International).

Kozolchyк, Boris (1979): "The commercialization of civil law and the civilization of commercial law", Lousiana Law Review, vol. XL, N 1: pp. 3-47.

Lando, Ole (2003): "Principles of European Contract Law and UNIDROIT Principles: moving from harmonisation to unification?”, Uniform Law Review, vol. VIII: pp. 123133. 
Marchese, Carl (2010): La lex mercatoria ed i rapporti con le law firms. Tesis doctoral (Milán, Università degli Studi di Milano). Disponible en: https:/air.unimi.it/retrieve/ handle/2434/155658/143163/phd_unimi_R07052.pdf Fecha de consulta: 12 de julio de 2016.

Masi, Pietro (2010): "Imprese minori e patti di famiglia", en AlPA, Guido et al. (edits.) Scritti in onore di Francesco Capriglione (Padova, CEDAM) pp. 1031-1041.

MasI, Pietro (2002): "Impresa Multinazionale", Enciclopedia del Diritto, vol. XLVI, N 6: pp. 508-525.

Mestre, Jacques (1986): “D’une exigence de bonne foi à un esprit de collaboration”, RTD Civ: p. 101.

Millon, David (1993): "Communitarians, contractarians, and the crisis in corporate law", Washington and Lee Review, vol. L: pp. 1373-1393.

MomberG, Rodrigo (2015): "La reforma al Derecho de las obligaciones y contratos en Francia. Un análisis preliminar", Revista Chilena de Derecho Privado, No 24: p. 121-142.

Mossa, Lorenzo (1926): "I problemi fondamentali del Diritto Commerciale", Rivista del Diritto Commerciale e del Diritto Generale delle Obbligazioni, vol. XXIV, parte prima: pp. 233-252.

Neal, Larry (1990): The rise of financial capitalism: international capital markets in the age of reason (Cambridge, Cambridge University Press).

Oppetit, Bruno (1991): "La experiencia francesa sobre codificación en materia comercial", en Centenario del Código de Comercio (México, Universidad Nacional Autónoma de México).

OrTs, Eric (2013): Business persons (Oxford, Oxford University Press).

Petrelli, Gaetano (2006): "La nuova disciplina del 'patto di famiglia", Rivista del Notariato, vol. II: pp. 401-447.

Rescigno, Pietro (2004): "La 'forma' codice: storia e geografia di una idea”, en Studi in onore di Piero Schlesinger (Milano, Giuffrè) pp. 217-224.

Rocco, Alfredo (1931): Principios de Derecho Mercantil (trad. de la Revista de Derecho Privado, Madrid, Librería General de Victoriano Suárez).

RÖDER, Tilmann, "The roots of the 'new law merchant': how the international standardization of contracts and clauses changed business law" Disponible en: http://www.forhistiur.de/zitat/0610roeder.htm Fecha de consulta: 12 de julio de 2016.

Rondinone, Nicola (2003): Storia inedita della codificazione civile (Milano, Giuffrè).

Sandoval, Ricardo (2009): Derecho Comercial, Tomo I (Santiago, Editorial Jurídica, séptima edición).

Schmidt, Karsten (1997): Derecho Comercial (trad. Federico Werner, Buenos Aires, Editorial Astrea, tercera edición).

Schneider, Uwe (1985): "La disciplina del finanziamento del 'Konzern'”, Rivista delle Società, año 30, No 4-5: pp. 995-1039.

SERra, Antonio (2004): “Considerazioni preliminari sulla nozione di 'Empresário”, Roma e America. Diritto Romano Comune, vol. XVII: pp. 81-92.

Siburu, Juan (1923): Comentario del Código de Comercio argentino. Tomo II (Buenos Aires, Librería Jurídica). 
Silva, Jesús María (2013): Fundamentos del Derecho Penal de Empresa (Madrid, Edisofer).

Stella, Mario (2014): Cesare Vivante e il "mito di fondazione" della scienza del Diritto Commerciale", Rivista del Diritto Commerciale e del Diritto Generale delle Obbligazioni, año CXII, fascículo 4: pp. 523-540.

STRASSER, Kurt (2004-2005): "Piercing the veil in corporate groups", Connecticut Law Review, vol. XXXVII: pp. 637-665.

SzTajn, Rachel (2004): Teoría jurídica da empresa (Editorial Atlas, São Paulo).

TAYLOR, Michael (1996): Herbert Spencer and the limits of the State (Bristol, Thoemmes Press).

Torres, Oscar (1998): "Las sociedades de hecho e irregular (con referencia a la sociedad colectiva comercial)", Revista de Derecho, vol. XIX: pp. 193-198.

UGarTe, José Luis (2013): "El concepto legal de empresa y el derecho laboral: cómo salir del laberinto', Revista Chilena de Derecho Privado, vol. XX: pp. 185-213.

URBINA, Ignacio (2011): "Levantamiento del velo corporativo", Revista Chilena de Derecho, vol. XXXVIII, N² 1: pp. 163-171.

ValladĀo, Erasmo y FrançA, Novaes (2013): “O 'Anteprojeto' de novo Código Comercial”, Revista Jurídica Consulex, No 400: pp. 32-37.

Van Alstine, Michael (1998): "Of textualism, party autonomy, and good faith", William \& Mary Law Review, vol. 40: pp. 1223-1312.

VÁsquez, Luis Guillermo y JuPPET, María Fernanda (2014): Derecho del tercer sector: corporaciones, fundaciones y cooperativas (Santiago, Thomson Reuters).

Veblen, Thorstein (2009): Teoría de la empresa de negocios (trad. Carlos Trípodi, Granada, Comares).

Vivante, Cesare (s.d.): Derecho Mercantil (trad. Francisco Blanco Constans, Madrid, Editorial La España Moderna).

VON FrIER, Friedrich (2009): “Zurück hinter die Aufklärung? Zur Wiedereinfiihrung von Verbandsstrafen“, Goltdammer's Archiv für Strafrecht, vol. CLVI, No 2: pp. 98-116.

Zamagni, Stefano y BRUni, Luigino (2013): Handbook on the economics of reciprocity and social enterprise (Northampton, Edward Elgar).

\section{NORMAS CITADAS}

Código Civil de Alemania $B G B(01 / 01 / 1900)$.

Código Civil de Francia (18/03/1804).

LeY 27/1999, de 16 de julio, de Cooperativas de España.

LeY N 10.406 (07/12/2002), que aprueba el texto del Código Civil brasileño.

Convención de Viena sobre Compraventa Internacional de Mercaderías (11/4/1980),

Diario Oficial, 3 de octubre de 1990.

LeY Orgánica No 5/2010 (22/6/2010) España, por la que se modifica la Ley Orgánica 10/1995 del Código Penal.

LeY N $55 / 2006$ (14/2/2006) Italia, Normas que modifican el Código Civil en materia de pacto de familia.

Regio Decreto No 262 (16/3/1942), que aprueba el Código Civil italiano. 
Código de Comercio de Chile (23/11/1865).

Decreto con Fuerza de Ley No 1 (16/05/2000), que fija el texto refundido, coordinado y sistematizado del Código Civil chileno.

Decreto Ley No 824 (31/12/1974) del Ministerio de Hacienda, que aprueba texto que indica de la ley sobre impuesto a la renta.

Decreto con Fuerza de Ley No 5 (23/9/2003), fija texto refundido, coordinado y sistematizado de la ley general de cooperativas.

LEY $N^{\circ} 19.499$ (11/4/1997), Establece normas sobre saneamiento de vicios de nulidad de sociedades y modifica Código de Comercio y otros cuerpos legales.

LeY $N^{\circ} 20.393$ (2/12/2009), Establece la responsabilidad penal de las personas jurídicas en los delitos de lavado de activos, financiamiento del terrorismo y delitos de cohecho que indica.

LEY N 20.667 (9/5/2013), Regula el contrato de seguros.

LEY N 20.720 (9/1/2014), Sustituye el régimen concursal vigente por una ley de reorganización y liquidación de empresas y personas, y perfecciona el rol de la superintendencia del ramo.

LEY N 20.760 (9/7/2014), Establece supuesto de multiplicidad de razones sociales consideradas un solo empleador, y sus efectos.

\section{JURISPRUDENCIA CITADA}

Cintas v. AMERICAN CAR AND Foundry Co., 131 N.J.Eq. 419 (1942).

Catrilef, Hernández, Salomón y otros con Pesca Cisne S.A. (2007): Corte Suprema, 23 de abril de 2008 (recurso de apelación y casación en la forma), Rol No 230-2007.

MARTINEZ CON SANTORO (2005): Corte Suprema, 26 de septiembre de 2005 (casación en la forma y en el fondo), rol: No 5483-2003, cita online: CL/JUR/6569/2005.

SoCIEDAd INMOBILIARIa E INVERSIONES RAMAQ LTDA CON GONZALO SANTOLAYA INGENIEROS CONSULTORES S.A. (2015): Corte de Apelaciones de Santiago, 13 de octubre de 2015 (recurso de apelación), rol No 2271-2015. 